\title{
No evidence for flooding stress memory in saplings of eight hardwood floodplain forest species
}

\author{
Melanie Schindler (i) - Franziska Schäfer • Tobias W. Donath (1) • \\ Kristin Ludewig $(\mathbb{D}$
}

Received: 29 October 2020/Accepted: 6 February 2021 / Published online: 23 February 2021

(C) The Author(s) 2021

\begin{abstract}
Alluvial floodplain forests became rare in many parts of Europe, due to anthropogenic changes. Therefore, restoration of floodplain forests is important, but a difficult task because of the complex environmental conditions. The zonation of woody species in floodplains is mainly determined by hydrological conditions, not only within one year but also during the previous years. Tolerance to flooding can be regarded as a key factor for the successful establishment. We examined whether a previous flooding
\end{abstract}

Communicated by Courtney Siegert.

M. Schindler $(\bowtie) \cdot$ F. Schäfer $\cdot$ K. Ludewig

Division of Landscape Ecology and Landscape Planning, Land Use and Nutrition (IFZ), Research Centre of Biosystems, Justus-Liebig-University Giessen, HeinrichBuff-Ring 26-32, 35392 Giessen, Germany

e-mail: melanie.schindler@umwelt.uni-giessen.de

F. Schäfer

e-mail: Franziska.schaefer@umwelt.uni-giessen.de

K. Ludewig

e-mail: Kristin.Ludewig@uni-hamburg.de

T. W. Donath

Department of Landscape Ecology, Institute for Natural

Resource Conservation, Christian-Albrechts-University

Kiel, Olshausenstraße 75, 24113 Kiel, Germany

e-mail: tdonath@ecology.uni-kiel.de

K. Ludewig

Applied Plant Ecology, Institute of Plant Science and Microbiology, University Hamburg, Ohnhorststraße 18, 22609 Hamburg, Germany showed an increased flooding tolerance of saplings from eight woody floodplain forest species after a recurrent flooding under controlled common garden conditions at the research station Gießen-Leihgestern (Germany). This would indicate a stress memory towards flooding stress. The individuals of the experiment already experienced a partial flooding of three different durations (three, six or nine weeks) or no flooding in the previous year. After nine months of recovery, these fourteen-month-old saplings were again either exposed to a partial flooding of nine weeks or no flooding. We assessed foliar injury and growth in terms of plant height, number of leaves and stem diameter three weeks (short-term recovery) and nine months (medium-term recovery) after flooding. The saplings showed no increased tolerance to a recurrent flooding irrespective of the previous experienced flooding duration. Therefore, no immediate stress memory towards flooding stress could be observed. To recover after flooding seems to be the better option compared to forming a stress memory, which explained that most species showed a decreased foliar injury after medium-term compared to shortterm recovery period.

\section{Introduction}

Floodplains form the transitional area between aquatic and terrestrial ecosystems along rivers (Richardson 
et al. 2007). The high small-scale heterogeneity results in an exceptionally high biodiversity (Tockner and Stanford 2002). In general, softwood floodplain forests can be found at sites with more frequent and prolonged flooding compared to hardwood floodplain forests, which are flooded less frequently and for shorter periods in Central Europe (Alaoui-Sossé et al. 2005).

Due to anthropogenic actions, such as building dikes, hardwood-floodplain forests are highly endangered ecosystems in many parts of Europe (Brunotte et al. 2009). In addition, altered dynamics of riparian ecosystems often led to strong changes in species composition and seem to trigger the establishment of non-native tree species (Hood and Naiman 2000; Rood et al. 2003). On top of this, climate change impacts on alluvial plant communities add to the uncertainty about adequate conservation and restoration measures in these habitats (Mosner et al. 2015). Therefore, the restoration of floodplain forests is needed to establish and preserve riparian biodiversity (Brunotte et al. 2009).

Flooding leads to water saturation of soil pores, causing substantial stress to terrestrial plants especially during the growing period (Leyer 2004). Thus, species that grow in floodplains must be adapted to changing water levels (Glenz et al. 2006) and flooding tolerance is certainly the key factor for these species to persist (Toner and Keddy 1997). Due to the low solubility and diffusion rates of oxygen in water, flooded plants experience hypoxic or anoxic conditions at their roots (Streng et al. 1989). Reduced oxygen availability leads to reduced photosynthesis (Streng et al. 1989), which in turn declines growth rate and biomass production and increases the injury to the flooded plants (Bockelmann et al. 2002).

Riparian plant species have developed different mechanisms to tolerate flooding (Vreugdenhil et al. 2006; Du et al. 2012). Most adaptations are morphological structures (Streng et al. 1989), such as hypertrophied lenticels, adventitious roots and aerenchyma tissues. Those structures increase the oxygen uptake and transport into the root system under flooded conditions (Cavers and Harper 1967). In scientific literature, conclusions on flooding tolerance have been mostly based on the responses during or immediately after the stress period. In contrast, long-term effects beyond the immediate impact of flooding are often neglected (Glenz et al. 2006). Indeed, flooding tolerance is the ability to survive flooding and to acclimate afterwards and must be thereby determined after a certain recovery period (Crisp et al. 2016; Schindler et al. 2020).

Flooding tolerance increases with age and developmental stage of the plants, respectively (Hauschild and Hein 2009). They are less sensitive towards flooding later in life and grow above the water level. Thus, species considered as flooding tolerant might be quite vulnerable to flooding during early establishment (Streng et al. 1989).

It has been shown that plants can form stress memories after stress events (Tahkokorpi et al. 2007; Walter et al. 2011), which can be defined as structural, genetic, and biochemical modification in plants (FletaSoriano and Munné-Bosch 2016). Those stress memories have been revealed as one mechanism for ecological and evolutionary success of plants to be prepared for future stress (Bruce et al. 2007). Some plant species are less negatively affected by environmental stress when they have already experienced the same stress earlier in their life (Crisp et al. 2016). Although, an increased tolerance to the same stress may compromise plant productivity in short-term, for example through a reduction of photosynthesis, it can lead to an increased tolerance to subsequent stress and therefore favour productivity in long-term (Bruce et al. 2007). Whether and when such memories would favour plants depend not only on the species, but also on the duration and severity of the stress to which the plants are exposed (Fleta-Soriano and Munné-Bosch 2016). For example, when the stress is too severe, productivity may also be negatively affected in both short- and long-term. In addition, there is an evidence that plants either are able to form stress memories or to recover after stress (Goh et al. 2003; Crisp et al. 2016). The latter would have a positive effect under unpredictable environmental conditions. The key role of this process seem to anchored in the RNA turnover, which can either facilitate recovery by clearing the stressresponsive transcriptome or by permitting memory formation by selectively stabilizing transcripts (Crisp et al. 2016).

To summarise, flooding tolerance depends on many different factors. Therefore, the success of restoration projects requires knowledge on the ecological, hydrological and geomorphological processes, as well as the flooding tolerance of the typical species (Streng et al. 1989). In addition, the question arises, whether there is 
a memory towards flooding stress for our investigated species and whether they are more likely formed after a certain flooding duration. Consequently, we investigated whether fourteen-month-old juveniles of eight hardwood floodplain forest species tolerate flooding better when they have already experienced flooding in the previous year. To this end, we examined the influence of a recurrent flooding on the short- and medium-term foliar injury and growth of juveniles under controlled common garden conditions. Specifically, we tested the following hypothesis in a greenhouse experiment:

1. Individuals will tolerate a flooding better (i.e. lower short- and medium-term foliar injury and higher growth in terms of plant height, number of leaves and stem diameter), when they already experienced a flooding the previous year.

2. There is a higher flooding tolerance (i.e. lower short- and medium-term foliar injury and higher growth in terms of plant height, number of leaves and stem diameter) the longer the previous flooding lasted.

\section{Methods}

Study species

As representatives for flooding tolerant hardwood floodplain forest species of northern Central Europe, we selected Quercus robur L., Fraxinus excelsior L., Cornus sanguinea L. and Crataegus monogyna Jacq. (Table 1). We also included the less flooding tolerant species Acer pseudoplatanus L. and Sambucus nigra L., which often occur in higher elevated hardwood floodplain forests (Table 1). In addition, we tested
Acer negundo L. and Fraxinus pennsylvanica Marshall, both native to North America, but also occurring in some hardwood floodplains in Central Europe.

Experimental setup

In autumn 2016, seeds of the study species were collected from trees in the active and former floodplain along the Middle Elbe River (in a range of NW $53^{\circ} 21^{\prime}$ $\mathrm{N}, 10^{\circ} 42^{\prime} \mathrm{E}$ and SE $52^{\circ} 58^{\prime} \mathrm{N}, 11^{\circ} 38^{\prime} \mathrm{E}$ ). After stratification, they were sown and grown in a greenhouse during April and May 2017 at the research station Linden-Leihgestern of the Justus-Liebig University (Giessen, Hesse/Germany, $50^{\circ} 32^{\prime} \mathrm{N}$, $\left.8^{\circ} 41^{\prime} \mathrm{E}\right)$. At the end of May, all emerged saplings were planted into pots $(6 \mathrm{~cm} \times 6 \mathrm{~cm} \times 7.5 \mathrm{~cm})$ and filled with a 1:1 mixture of sand and commercial potting soil (Fruhstorfer Erde ${ }^{\circledR}$, Type P, IndustrieErdenwerke Archut GmbH, Lauterbach/Germany). This soil is suitable especially for juveniles and provides standardized substrate in the experiment. Afterwards, they were set up outdoors on a paved area exposed to ambient light, wind, temperature and precipitation. During summer 2017, when the saplings were six weeks old, they were subjected to an experimental flooding with different flooding durations $(k=4)$ : no, short (three weeks), medium (six weeks) and long (9 weeks; Fig. 1a). Therefore, the saplings were randomly assigned to basins of the corresponding flooding duration and covered with tap water until $2 \mathrm{~cm}$ above the pot rim, i.e. plants were not completely submerged. Twelve weeks after the experiment started, including a recovery period of at least three weeks for the longest flooding duration, foliar injury and growth in terms of plant height, number of leaves and stem diameter were recorded. The foliar injury was documented using five injury classes (1: all
Table 1 Information about study species, their family and flooding tolerance (including citations)

The nomenclature of plant species follows Rothmaler et al. (2017)

\begin{tabular}{lll}
\hline Species & Family & Flooding tolerance \\
\hline A. negundo & Sapindaceae & High (Starfinger et al. 2011) \\
A. pseudoplatanus & Sapindaceae & Low (Siebel and Bouwma 1998) \\
C. sanguinea & Cornaceae & Intermediate (Glenz 2005) \\
C. monogyna & Rosaceae & Intermediate (Siebel and Bouwma 1998) \\
F. excelsior & Oleaceae & High (Glenz 2005) \\
F. pennsylvanica & Oleaceae & High (Tang and Kozlowski 1984) \\
Q. robur & Fagaceae & High (Glenz 2005) \\
S. nigra & Adoxaceae & Low (Glenz 2005) \\
\hline
\end{tabular}




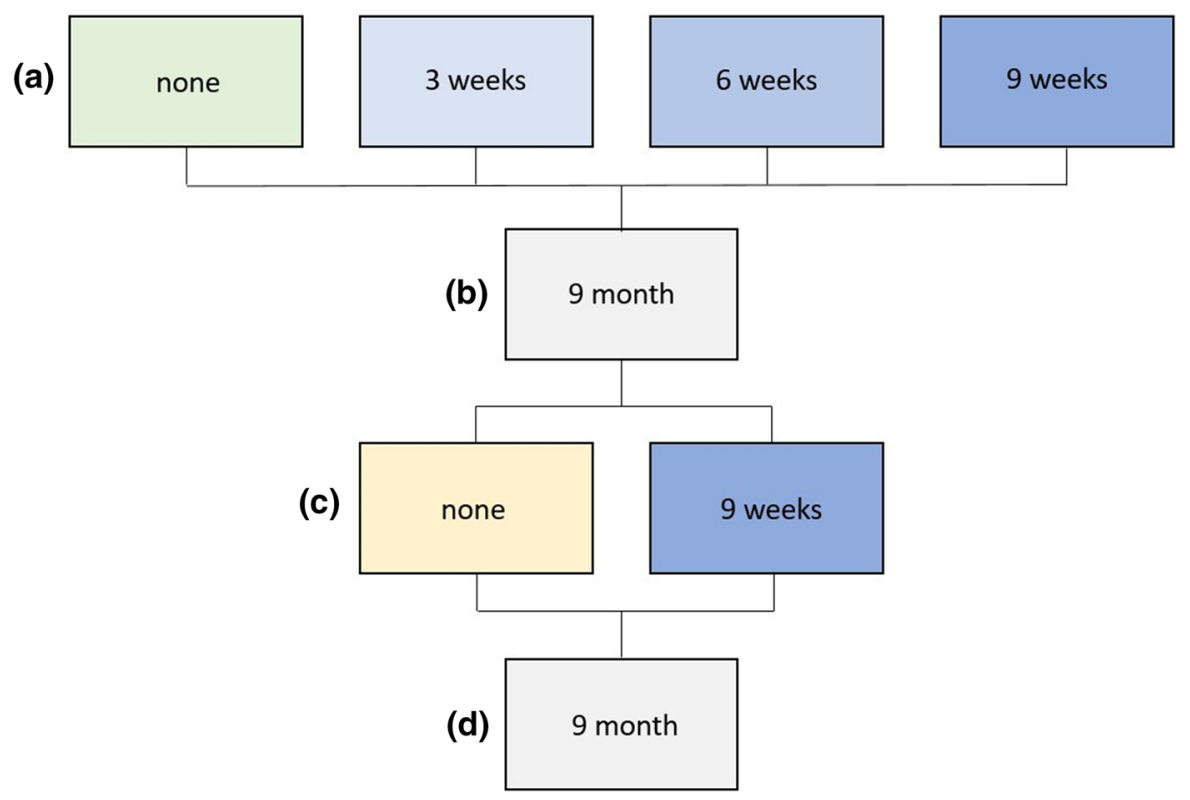

Fig. 1 Study design a previous flooding duration, b previous recovery time, $\mathbf{c}$ new flooding treatment, $\mathbf{d}$ recovery time

leaves undamaged, 2: all leaves fully developed but show damage $<50 \%$, 3: leaves not fully developed and damaged $>50 \%$, 4: all leaves damaged or dead, but plant is still alive, 5: plant dead). For medium-term recovery, foliar injury was additionally recorded after nine months recovery, which was just before the recurrent flooding started in 2018 (Fig. 1b). In the meantime, the plants were repotted into larger pots (11 $\mathrm{cm} \times 11 \mathrm{~cm} \times 12 \mathrm{~cm}$ ) and watered as needed to ensure optimal conditions during their recovery period. For more details on the first flooding experiment, see (Schindler et al. 2020).

During summer 2018, the fourteen-month-old saplings were subjected to a new flooding. The factor levels were either nine weeks of flooding or no flooding ( $k=2$; Fig. 1c). Due to mortality of the first flooding experiment, altogether 348 individuals were available for the second flooding experiment, i.e. 48 individuals each of $A$. negundo, C. monogyna and $F$. pennsylvanica, 46 individuals of $Q$. robur, 44 individuals of $S$. nigra, 41 individuals of A. pseudoplatanus, 40 individuals of $C$. sanguinea and 33 individuals of $F$. excelsior.

From June to September 2018, the experiment was set up outdoors on the same paved area as in the previous year. Altogether, six flooding basins comprising wooden frames of $1.5 \mathrm{~m}^{2}$ lined with a $0.2 \mathrm{~mm}$ thick waterproof silage film (with the bright side upwards) were prepared of which three of them were flooded nine weeks (flooded treatment) and three of them were not flooded (unflooded treatment). This setup resulted in a split-plot design, i.e. each treatment was located in one block (i.e. basin) thrice to ensure manageability and repetitions. The treatment groups were randomly assigned to the six basins. Within each basin, we allocated approximately the same number of plants from all previous flooding durations and from the unflooded control. The pots were randomly distributed within the basins and positions were changed every three weeks. The flooded basins were again filled with tap water up to $2 \mathrm{~cm}$ above the pot rim. To counteract uplift the pots were weighted with stones. When necessary, evaporated water was refilled to keep the water level constant during the flooding period. Pots in unflooded treatment basins were regularly irrigated to keep the soil constantly moist.

At the beginning (June 14th 2018) and after a shortterm recovery period of three weeks after the completion of the experiment (September 6th 2018), foliar injury and growth in terms of plant height, number of leaves and stem diameter were recorded. The height of the plants was determined by measuring the distance between root collar and terminal bud. In addition, the number of leaves was counted and the stem diameter at the soil surface was measured using calipers. Afterwards the differences $(\Delta)$ between plant 
height, number of leaves and stem diameter from before to after the experiment were calculated. Due to leaf loss or the death of upper shoots, negative values could occur. If several stems existed, the sum stem diameter was used. As in the previous year, foliar injury was assessed using a scale with five classes. In June 2019 foliar injury was recorded again after a medium-term recovery period of nine months (Fig. 1d).

\section{Statistical analyses}

We analyzed the effect of the previous flooding, the flooding duration as well as the new flooding treatment on the foliar injury of the saplings by conducting nonparametric Scheirer-Ray-Hare-Tests due to the fact that foliar injury was not normal distributed (Puri and Sen 1985). As response variables, the parameters 'short-term foliar injury' and 'medium-term foliar injury' were used. We computed separate ScheirerRay-Hare-Tests for each species for both response variables with the factors previous flooding duration (none, short, medium, long), the new flooding treatment (yes, no) and their interaction (Crawley 2007). For post hoc testing, we used the Dunn Kruskal-Wallis multiple comparison with Benjamini-Hochberg adjusted $p$ values (Puri and Sen 1985). To compare short- and medium-term foliar injury for each species, the response variable 'foliar injury' was used and separate Scheirer-Ray-Hare-Tests were calculated including the factor time (3 weeks, 9 months).

We analyzed the effect of the previous flooding, the previous flooding duration and the new flooding treatment on the growth of the saplings by conducting several ANOVAs for split-plot designs (Crawley 2007). As response variables, ' $\Delta$ plant height', ' $\Delta$ number of leaves' and ' $\Delta$ stem diameter' were used. Dead plants were excluded from the analyses to avoid the detrimental effects of zero values on the ANOVA results. Consequently, if there was a high mortality within a treatment, no $p$ values could be calculated. We computed separate ANOVAs for each species for all response variables with the factors previous flooding duration (none, short, medium, long) and new flooding treatment (yes, no) and their interaction. Those were nested in the factor treatment (summarized to two different treatments, where basins 1-3 were flooded and basins 4-6 were the unflooded treatment to ensure manageability) and included in the error term for the split-plot setup (Crawley 2007). In order to calculate the relative contribution of each factor or each interaction to the total variance, the sum of squares of a factor or an interaction was divided by the total sum of squares (Crawley 2007). We visually checked diagnostic plots to test the preconditions of ANOVAs (e.g. normal distribution, variance homogeneity; Quinn and Keough 2002). For the post hoc pairwise t-tests Holm adjusted $p$ values were used (Crawley 2007).

The significance level for all analyses was $\alpha=0.05$. All statistical analyses and figures were carried out using the $\mathrm{R}$ software environment ( $\mathrm{R}$ Development Core Team 2017).

\section{Results}

Overview summarised for all species

In general, neither the previous flooding nor its duration showed an effect on the short- and mediumterm foliar injury (Fig. 2). Only the newly flooded individuals showed a higher short-term and mediumterm foliar injury, which means around one class worse compared to the unflooded treatment ( $p$ value $\leq$ 0.001; Fig. 2). Overall, after medium-term recovery, foliar injury decreased of approx. half a class but varied over a greater range compared to short-term foliar injury (Fig. 2).

With an averaged loss of six leaves, the $\Delta$ number of leaves was slightly lower for the previously flooded individuals compared to no changes in leaf number for the individuals that experienced no flooding ( $p$ value $=$ 0.02; Fig. 3). Apart from that, the growth did not differ dependent on the previous flooding or its duration. The newly flooded individuals showed an almost constant plant height and lost up to 25 leaves, whilst the unflooded ones grew an average of three $\mathrm{cm}$ and did not show any changes in number of leaves ( $p$ values $\leq$ 0.001; Fig. 3).

Species-specific differences in foliar injury

The newly flooded individuals of A. pseudoplatanus $(p$ value $\leq 0.001)$ and $F$. excelsior $(p$ value $=0.011)$ performed around one to one and a half injury classes worse compared to the unflooded individuals after short-term recovery. For C. monogyna they were 



Fig. 2 Foliar injury summarised for all species depending on the previous flooding (left) and its duration (right) after shortterm recovery of three weeks (top) and after medium-term recovery of nine months (bottom); Injury classes from 1

classified around two classes worse after short-term ( $p$ value $\leq 0.001)$ and around half a class worse after medium-term recovery $(p$ value $=0.005)$. All newly flooded $C$. sangiunea and $S$. nigra individuals showed a $100 \%$ leaf damage or were even dead, whilst no or only less damage was visible for the unflooded individuals $(p$ values $\leq 0.001$ ). In contrast, there was almost no leaf damage of the newly flooded individuals of $A$. negundo ( $p$ value $=0.03$ ), whilst most individuals of the unflooded treatment showed a low leave damage of under $50 \%$ after medium-term recovery (Fig. 4).

When comparing short- and medium-term foliar injury for the newly flooded individuals, the individuals of A. pseudoplatanus ( $p$ value $=0.011$ ) and $F$. pennsylvanica ( $p$ value $\leq 0.001$ ) decreased of around one class, A. negundo ( $p$ value $\leq 0.001)$ and $F$.

(without damage) to 5 (dead); $\mathrm{w}=$ weeks; Significant differences between the main effects are indicated with capital letters $\left(\mathrm{PF}^{*}\right.$ - previous flooding, $\mathrm{FD}^{*}$ - previous flooding duration, $\mathrm{NF}^{*}$ - new flooding treatment)

excelsior ( $p$ value $\leq 0.001$ ) of approx. one to two classes and $C$. monogyna ( $p$ value $\leq 0.001$ ) of two classes after nine months recovery (Fig. 4).

Overall, there were species-specific differences in foliar injury. For example, in the new flooding treatment, A. pseudoplatanus showed a higher foliar injury of around one class compared to $F$. excelsior, $A$. negundo and $F$. pennsylvanica ( $p$ value $\leq 0.001$ ), but approx. a half class lower compared to $S$. nigra and $C$. sanguinea, which showed the highest foliar injury of all species (Fig. 4).

Species-specific differences in $\Delta$ growth

The previously flooded individuals of $F$. excelsior showed no change in number of leaves, whilst the previously unflooded ones showed an increase of 

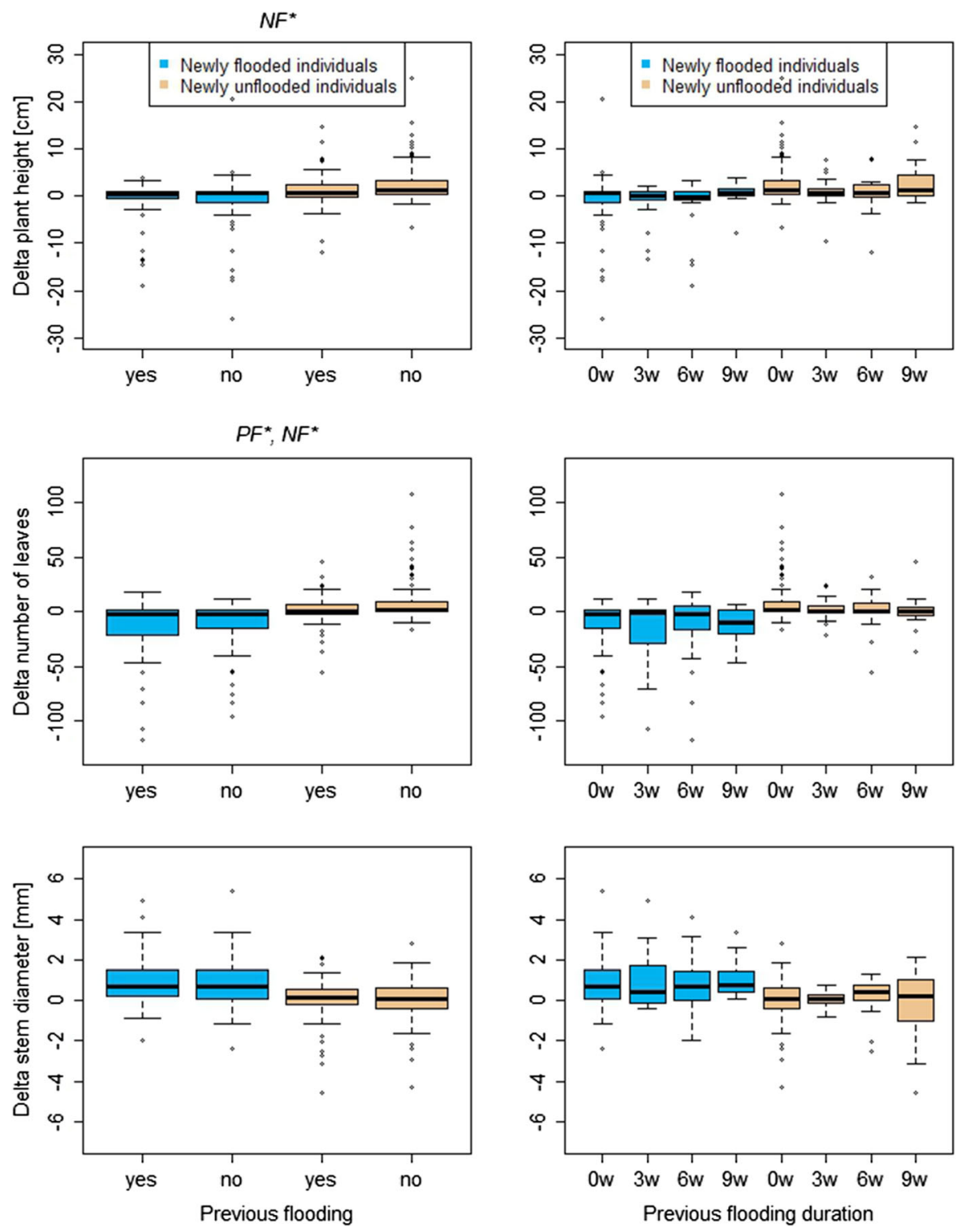

Fig. $3 \Delta$ growth ( $\Delta$ plant height, $\Delta$ number of leaves, $\Delta$ stem diameter) summarised for all species depending on the previous flooding (left) and its duration (right) after short-term recovery of three weeks; w = weeks; Significant differences between the

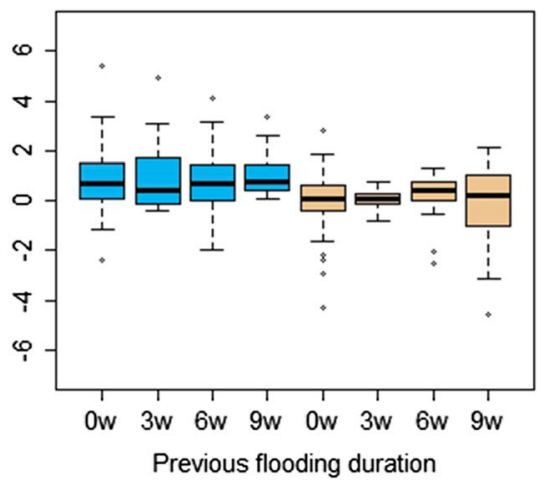

main effects are indicated with capital letters $\left(\mathrm{PF}^{*}\right.$ - previous flooding, $\mathrm{FD}^{*}$ - previous flooding duration, $\mathrm{NF}^{*}$ - new flooding treatment)

averaged 6 leaves $(p$ value $=0.03)$. C. sanguinea $(p$ value $=0.037)$ had an approx. two mm lower $\Delta$ stem diameter compared to the previously unflooded individuals (Figs. 6 and 7). There were no differences in $\Delta$ growth parameter depending on the previous flooding or its duration for the other species.

The newly flooded individuals of A. pseudoplatanus $(p$ value $\leq 0.001), C$. monogyna $(v$ value $=0.001)$ and $C$. sanguinea ( $p$ value $\leq 0.001$ ) showed a ten, five

and ten $\mathrm{cm}$ lower $\Delta$ plant height, respectively and a lower $\Delta$ number of leaves of up to 60 leaves for $C$. monogyna compared to the unflooded individuals (Figs. 5 and 6). The newly flooded individuals of $F$. pennsylvanica showed a slightly lower $\Delta$ number of leaves ( $p$ value $=0.039$ ) but a $2.5 \mathrm{~mm}$ higher $\Delta$ stem diameter $(p$ value $\leq 0.001)$ compared to the unflooded ones (Figs. 6 and 7). A higher $\Delta$ stem diameter of one to two $\mathrm{mm}$ for the flooded compared to the unflooded 

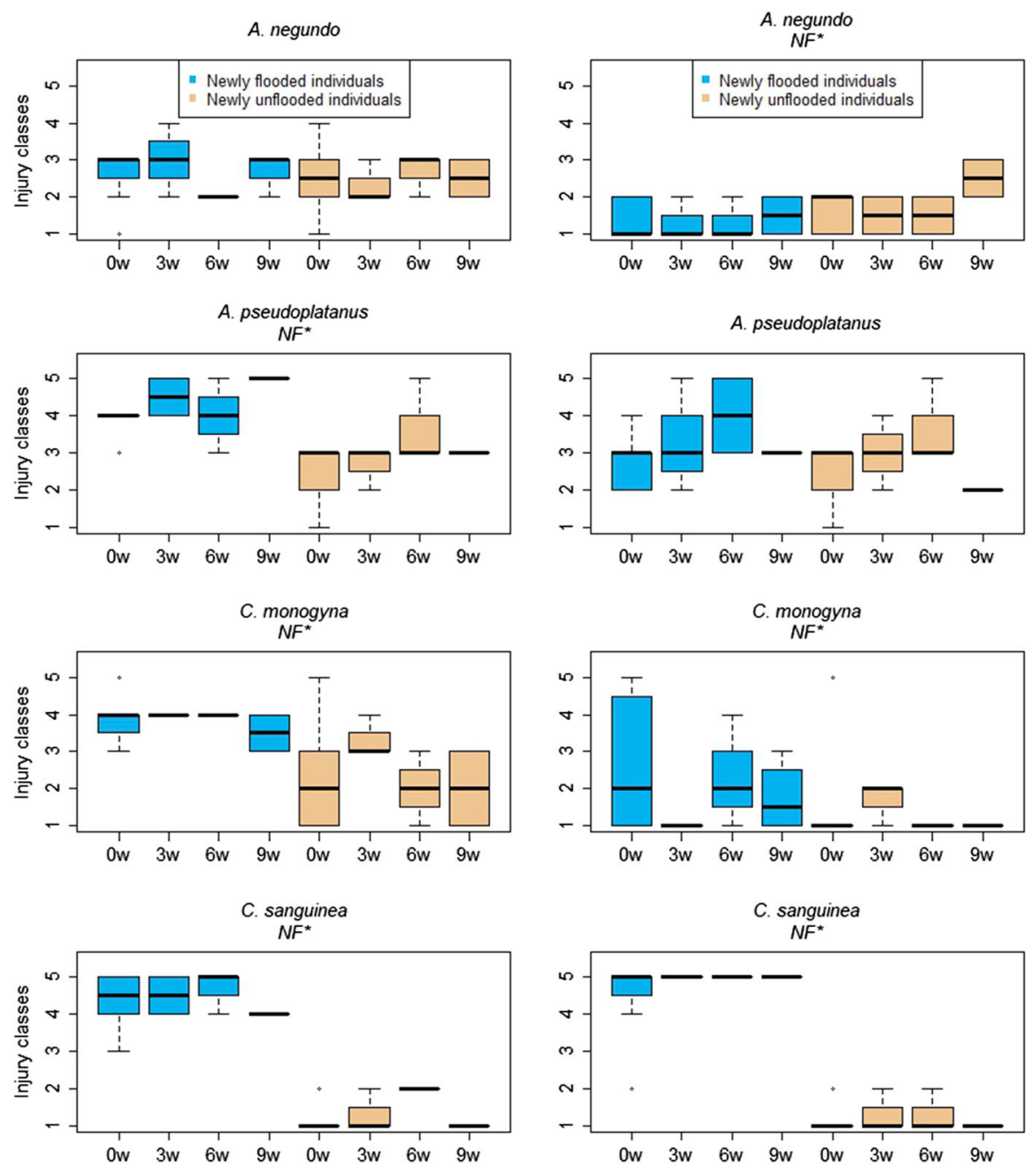

Fig. 4 Foliar injury of each species depending on the previous flooding duration after short-term (left) and medium-term recovery of nine months (right); Injury classes from 1 (without damage) to 5 (dead); $w=$ weeks; Significant differences between

the main effects were marked with capital letters $\left(\mathrm{PF}^{*}\right.$ previous flooding, $\mathrm{FD}^{*}$ - previous flooding duration, $\mathrm{NF}^{*}$ new flooding treatment)

individuals was also visible for $A$. negundo ( $p$ value $\leq$ $0.001), F$. excelsior $(p$ value $\leq 0.001)$ and $Q$. robur ( $p$ value $=0.003)$, whilst the reverse was true for $C$. monogyna $(p$ value $=0.004 ;$ Fig. 7$)$.

\section{Discussion}

Contrary to our expectations, both hypotheses must be rejected. The flooding tolerance in terms of foliar injury or growth of our investigated saplings did not improve due to a previous flooding or increasing flooding duration. Although it is widely accepted that

plants have the capacity for what can be described as memory, in many instances, such memories cannot be observed. Ding et al. (2012) reported that multiple exposures to drought stress enable plants to respond to the same stress by more rapid adaptation compared to plants not previously exposed to drought stress. However, there is also evidence that such stress memories can have negative effects by hindering the recovery and therefore preventing the plant from maximizing growth as soon as favourable conditions occur (Crisp et al. 2016). Those negative effects were observed in particular in response to severe stress (Davies et al. 1992). For example in the study of 

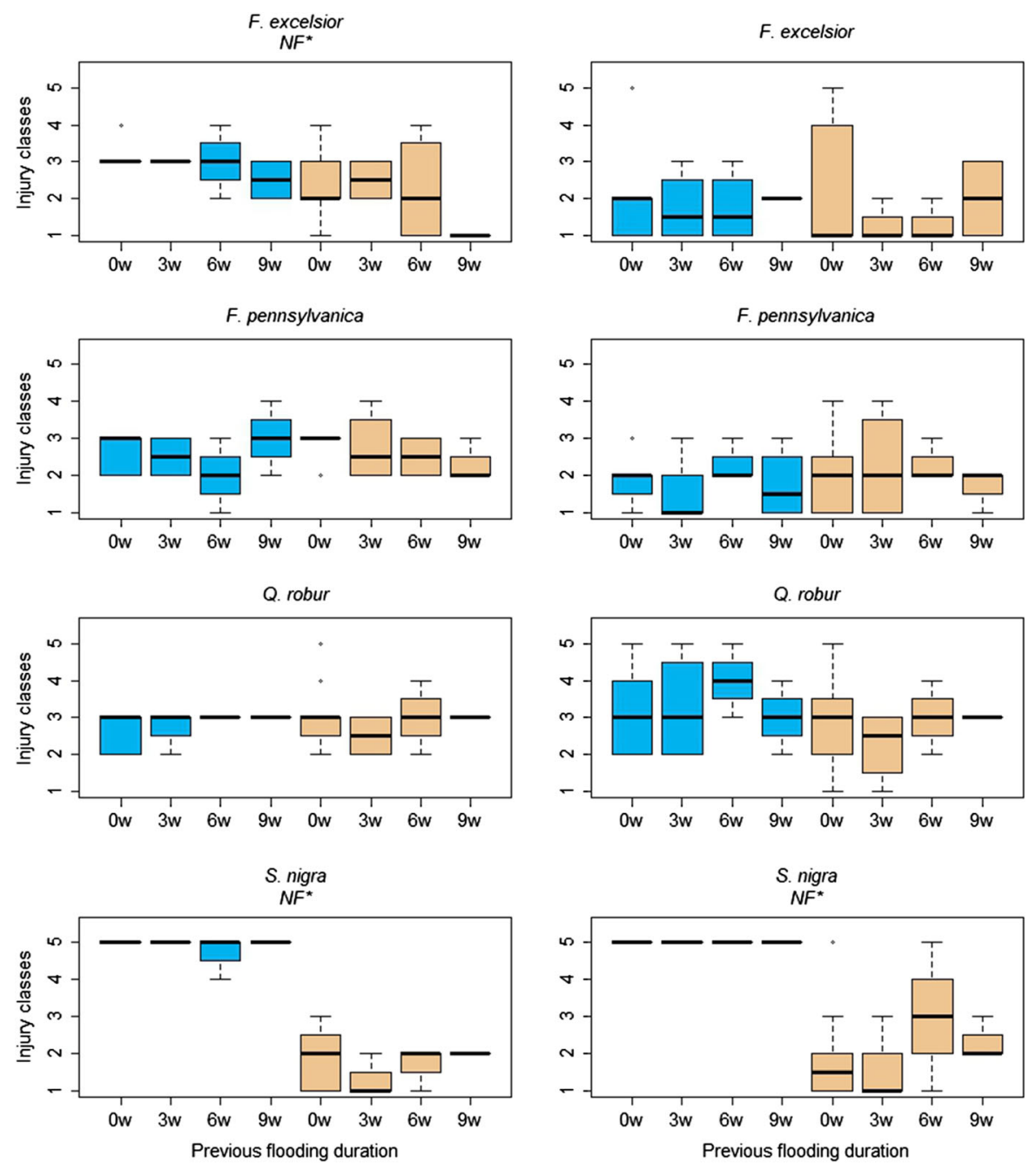

Fig. 4 continued

Walter et al. (2011), severe drought stress in grasses resulted in biomass loss and reduction in photosynthesis when plants were challenged by a second drought, whilst Backhaus et al. (2014) found out that mild drought stress seems to improve drought resistance of grassland species. Therefore, the stress level seems to be a decisive factor in whether a stress memory is formed or not.

On the one hand, the flooding stress of nine weeks alone could have been too severe for some species such as $C$. sanguinea, which showed a high injury and reduced growth after the new flooding treatment only. C. sanguinea also point out a high mortality and increased foliar injury with increasing flooding duration, after the first flooding (Schindler et al. 2020), probably because this species is only capable of forming adventitious roots (Polomski and Kuhn 1998; Glenz et al. 2006). Therefore, the flooding of nine weeks alone, irrespective of previous flooding seems to damage the individuals of $C$. sanguinea to the extent that they are unable to recover. This fits to the study of Siebel and Bouwma (1998), who found that young shrubs of $C$. sanguinea only occur on high areas of the hardwood floodplain forests, which are flooded only a few days a year.

On the other hand, the nine weeks of flooding could have been too low for the highly flooding tolerant species such as $A$. negundo and $F$. pennsylvanica. They have the ability to form lenticels and adventitious roots very quickly after flooding (Hook and 

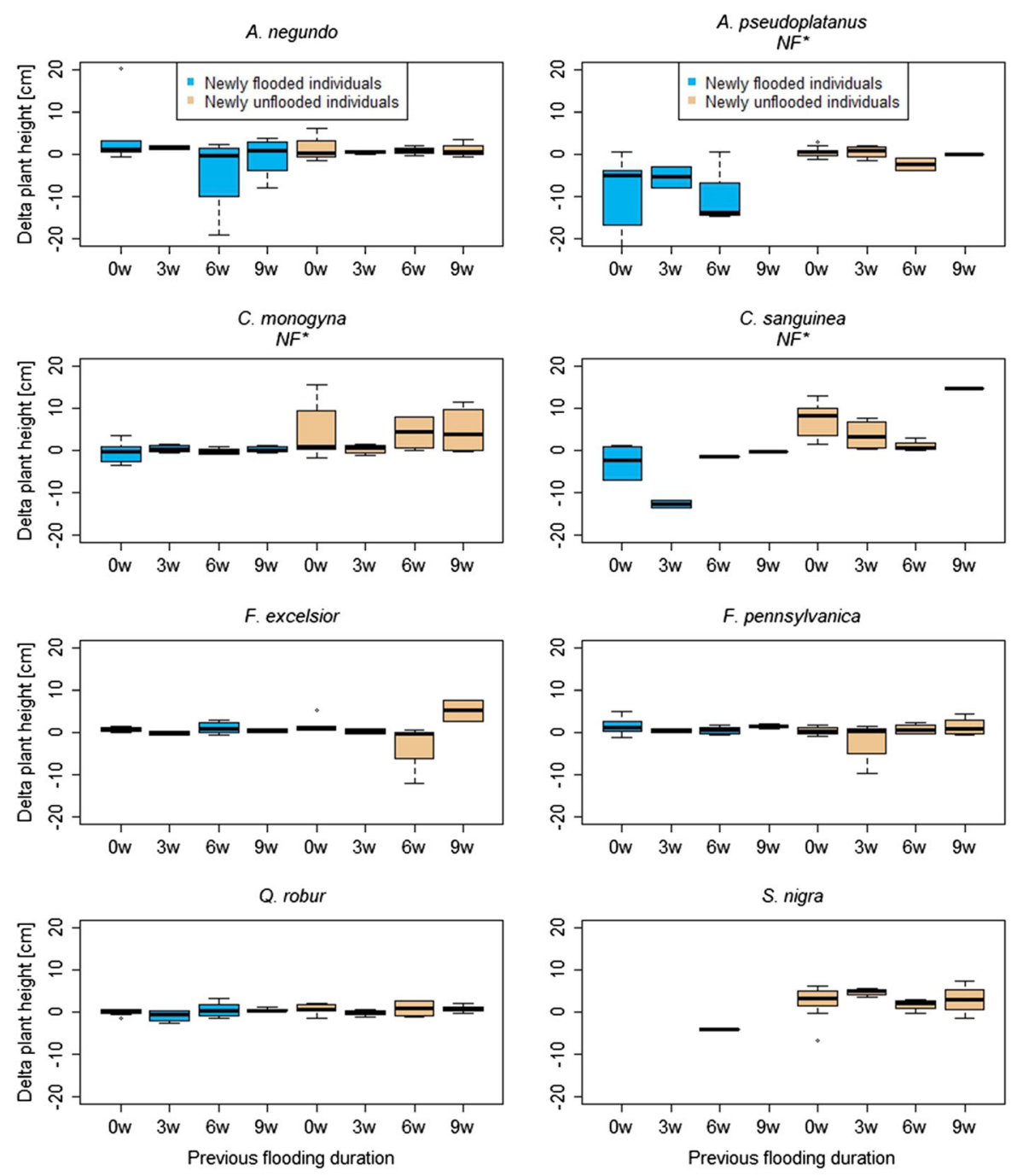

Fig. $5 \Delta$ Plant height of each species depending on the previous flooding duration after a short-term recovery of three weeks; $w=$ weeks; Significant differences between the main effects were

Brown 1973; Tang and Kozlowski 1984) and are able to survive flooding periods of up to $50 \%$ of their growing season without any damage (Zacharias and Breucker 2008). This fast stress response would probably make a stress memory superfluous. Furthermore, we only repeated the flooding stress twice and not like Ding et al. (2012) several times. Possibly a memory is formed after several stress repetition. Another possibility would be that the probability to form a stress memory in long-lived trees increases in the course of life, just like flooding tolerance increases with age. Zweifel et al. (2020) for example found a delayed drought stress response in terms of restricted

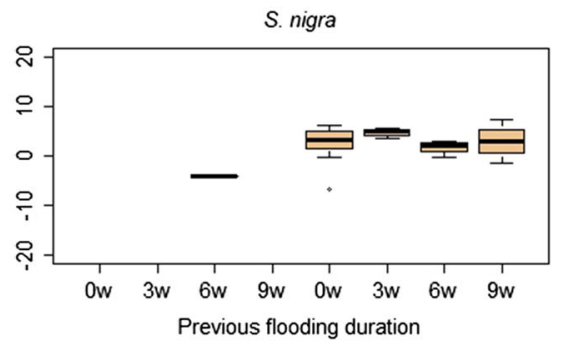

marked with capital letters $\left(\mathrm{PF}^{*}\right.$ - previous flooding, $\mathrm{FD}^{*}$ previous flooding duration, $\mathrm{NF}^{*}$ —new flooding treatment)

growth in mature pine trees after two to four year after drought. We only focused on the first two years of the establishment phase, which might be too short for final conclusions.

Furthermore, there appear to be two main strategies after stress events, where plants seem to balance between investing resources in stress memory or recovery from stress damage (Crisp et al. 2016). Flooding duration and -frequency are often unpredictable under natural conditions (Zhou et al. 2020). Hence, the predominant strategy for our species appear to recover after flooding, which seems to be the more successful option under 

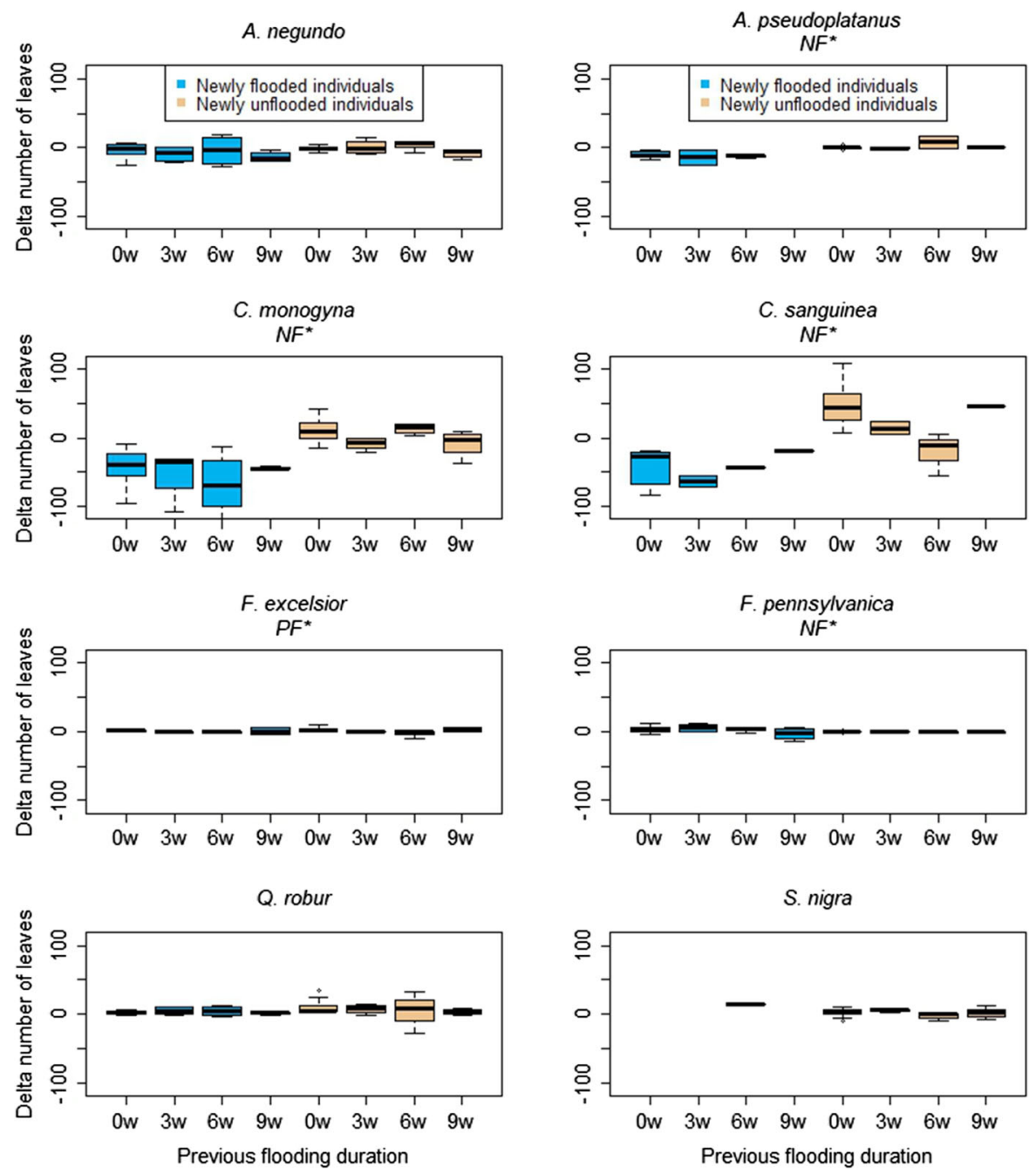

Fig. $6 \Delta$ Number of leaves of each species depending on the previous flooding duration after a short-term recovery of three weeks; w = weeks; Significant differences between the main

unpredictable environmental conditions (Bruce et al. 2007) and would explain the lower foliar injury after medium-term recovery period for most of the investigated species. Especially F. excelsior and C. monog$y$ y a recovered very well after a recovery period of nine months. Nevertheless, the previously flooded individuals of $F$. excelsior showed a higher leaf loss compared to the previously unflooded individuals, which is in accordance with the flooding experiment of Frye and Grosse (1992), where flooded F. excelsior saplings showed a reduced aboveground biomass compared to unflooded individuals the following year. This reaction might be an adaptive strategy by

effects were marked with capital letters (PF*-previous flooding, $\mathrm{FD}^{*}$ - previous flooding duration, $\mathrm{NF}^{*}$ - new flooding treatment)

reducing energy consumption (Pires et al. 2018). New leaves only sprout when environmental conditions become better (Mommer and Visser 2005; Pires et al. 2018). The fast recovery of $F$. excelsior and $C$. monogyna was also observed after the first flooding in the previous year and confirms that poor performance during flooding does not necessarily indicate a reduced flooding tolerance, as some species can save energy for later recovery (Schindler et al. 2020; Striker 2012).

The development of plants after nine months recovery can not only improve, but also deteriorate for some species and lead to even greater damage 

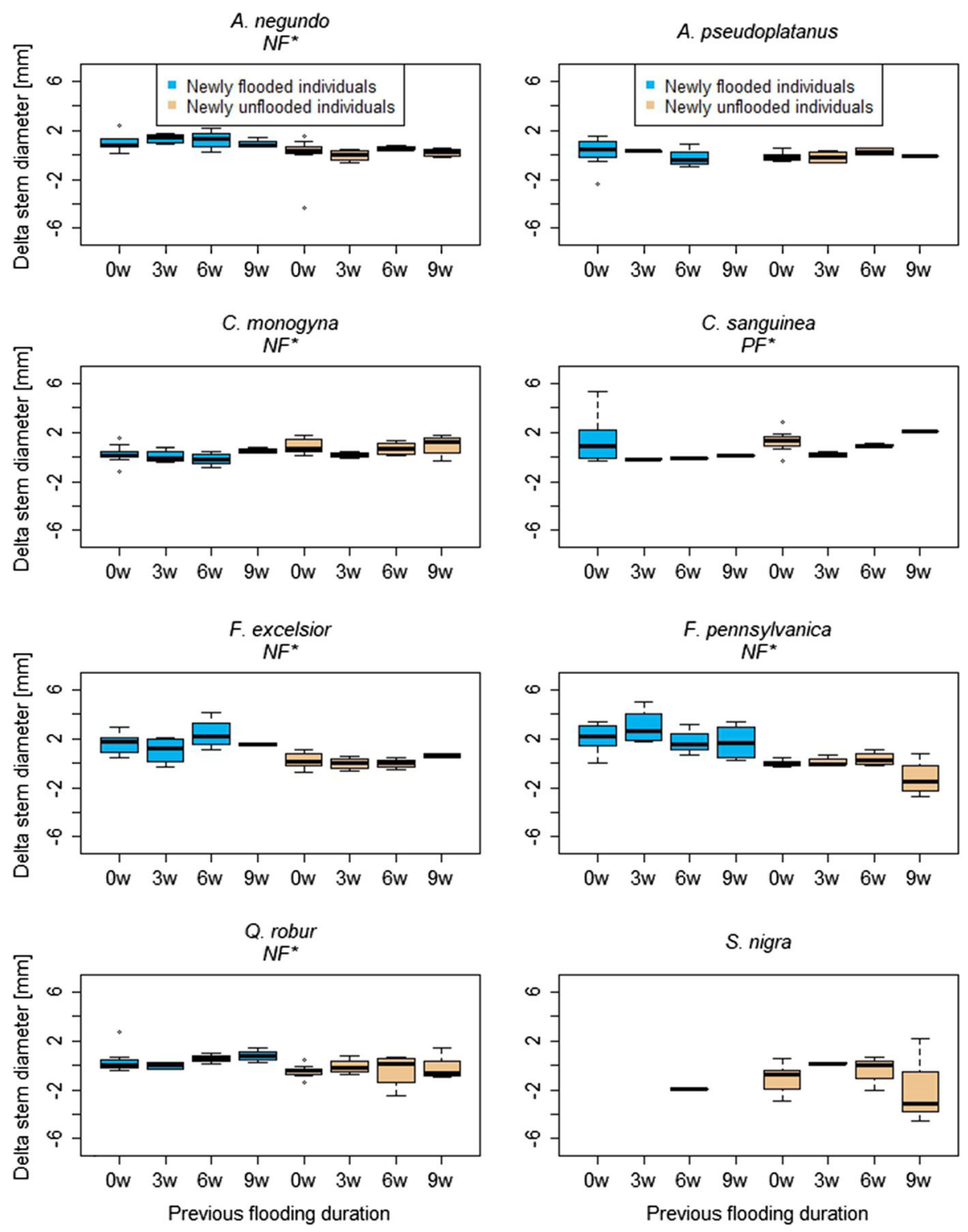

Fig. $7 \Delta$ Stem diameter of each species depending on the previous flooding duration after a short-term recovery of three weeks; w = weeks; Significant differences between the main

effects were marked with capital letters (PF*-previous flooding, $\mathrm{FD}^{*}$ - previous flooding duration, $\mathrm{NF}^{*}$ - new flooding treatment)

(Striker 2012). For example, S. nigra showed a low short-term injury, but a high medium-term injury after the first flooding (Schindler et al. 2020). After the new flooding of nine weeks, there was a high short- and medium-term foliar injury. Flood damage effects may persist for up to three years and the time between floods, may result in an additional weakening for some species. This could also explain the lower $\Delta$ stem diameter of the previously flooded individuals of $C$. sanguinea compared to the previously unflooded ones.

A second flooding without a sufficiently long recovery period especially during the early sapling stages could lead to even greater damage (Striker 2012). Therefore, a longer recovery period before the second flooding could have contributed positively especially to the less flooding tolerant species.

Another example for the potential of stress memories in plants becomes apparent in the study of (Ferreira et al. 2007), where they determined the influence of flooding tolerance on seedlings from a 
floodplain versus upland population of the same species (Himatanthus sucuuba). They found out that the floodplain population was more tolerant to flooding in terms of a higher germination rate, survival and growth rate than the upland population. Therefore, there is evidence that such memories can be passed down to offspring to increase their success. We collected most of the seeds in the former floodplain where these effects may not have occurred but it would be interesting to repeat the experiment with seeds from the active versus the former floodplain.

\section{Conclusion}

Contrary to our expectations, a previous flooding, regardless of its duration showed no increased flooding tolerance of the saplings. Therefore, no stress memory towards flooding stress could be observed for our investigated species. The predominant strategy here seems to be recovery after flooding. Therefore, recurring floods without an adequately long recovery period could pose problems for the establishment of saplings in floodplains, especially under changing climatic conditions with increasingly unpredictable and extreme flooding events (Mosner et al. 2015). Due to the complexity of interacting processes, the knowledge about flooding tolerance especially in terms of stress memory and stress recovery needs further investigation.

Acknowledgements We thank Annette Otte for supporting the work at the Institute, Josef Scholz-vom Hofe for assistance in growing the plants and data collection and Carl Beyboer for proofreading the English. The German Federal Institute of Hydrology [Grant Number U2/Z1/064.31-016/16/1479] financed this work.

Funding Open Access funding enabled and organized by Projekt DEAL..

Open Access This article is licensed under a Creative Commons Attribution 4.0 International License, which permits use, sharing, adaptation, distribution and reproduction in any medium or format, as long as you give appropriate credit to the original author(s) and the source, provide a link to the Creative Commons licence, and indicate if changes were made. The images or other third party material in this article are included in the article's Creative Commons licence, unless indicated otherwise in a credit line to the material. If material is not included in the article's Creative Commons licence and your intended use is not permitted by statutory regulation or exceeds the permitted use, you will need to obtain permission directly from the copyright holder. To view a copy of this licence, visit http://creativecommons.org/licenses/by/4.0/.

\section{References}

Alaoui-Sossé B, Gérard B, Binet P, Toussaint ML, Badot PM (2005) Influence of flooding on growth, nitrogen availability in soil, and nitrate reduction of young oak seedlings (Quercus robur L.). Ann Forest Sci 62:593-600. https:// doi.org/10.1051/forest:2005052

Backhaus S, Kreyling J, Grant K, Beierkuhnlein C, Walter J, Jentsch A (2014) Recurrent mild drought events increase resistance towards extreme drought stress. Ecosystems 17:1068-1081. https://doi.org/10.1007/s10021-014-97815

Bockelmann AC, Bakker JP, Neuhaus R, Lage J (2002) The relation between vegetation zonation, elevation and inundation frequency in a Wadden Sea salt marsh. Aquat Bot 73:211-221. https://doi.org/10.1016/S03043770(02)00022-0

Bruce TJA, Matthes MC, Napier JA, Pickett JA (2007) Stressful "memories" of plants: evidence and possible mechanisms. Plant Sci 173:603-608. https://doi.org/10.1016/j.plantsci. 2007.09.002

Brunotte E, Dister E, Günther-Diringer D, Koenzen U, Mehl D (2009) Auenzustandsbericht. Flussauen in Deutschland: Erfassung und Bewertung des Auenzustandes. Naturschutz und Biologische Vielfalt 87:1-244

Cavers PB, Harper JL (1967) Studies in the dynamics of plant populations: I. The fate of seed and transplants introduced into various habitats. J Ecol 55:59-71. https://doi.org/10. 2307/2257716

Crawley MJ (2007) The R book. Hoboken, N.J, Wiley, Chichester, England

Crisp PA, Ganguly D, Eichten SR, Borevitz JO, Pogson BJ (2016) Reconsidering plant memory: intersections between stress recovery, RNA turnover, and epigenetics. Sci Adv 2:e1501340. https://doi.org/10.1126/sciadv.1501340

Davies FT, Potter JR, Linderman RG (1992) Mycorrhiza and repeated drought exposure affect drought resistance and extraradical hyphae development of pepper plants independent of plant size and nutrient content. J Plant Physiol 139:289-294. 1617(11)80339-1 https://doi.org/10.1016/S0176-

Ding Y, Fromm M, Avramova Z (2012) Multiple exposures to drought "train" transcriptional responses in Arabidopsis. Nat Comm 3:740. https://doi.org/10.1038/ncomms 1732

Du K, Xu L, Wu H, Tu B, Zheng B (2012) Ecophysiological and morphological adaption to soil flooding of two poplar clones differing in flood-tolerance. Flora - Morphol Distribut Funct Ecol Plants 207:96-106. https://doi.org/10. 1016/j.flora.2011.11.002

Ferreira CS, Piedade MTF, Junk WJ, Parolin P (2007) Floodplain and upland populations of Amazonian Himatanthus sucuuba: Effects of flooding on germination, seedling growth and mortality. Environ Exp Bot 60:477-483. https://doi.org/10.1016/j.envexpbot.2007.01.005 
Fleta-Soriano E, Munné-Bosch S (2016) Stress memory and the inevitable effects of drought: a physiological perspective. Front Plant Sci. https://doi.org/10.3389/fpls.2016.00143

Frye J, Grosse W (1992) Growth responses to flooding and recovery of deciduous trees. Zeitschrift für Naturforschung C 47:683-689. https://doi.org/10.1515/znc-1992-9-1008

Glenz C (2005) Process-based, Spatially-explicit Modelling of Riparian Forest Dynamics in Central Europe - Tool for Decisionmaking in River Restoration.

Glenz C, Schlaepfer R, Iorgulescu I, Kienast F (2006) Flooding tolerance of Central European tree and shrub species. For Ecol Manag 235:1-13. https://doi.org/10.1016/j.foreco. 2006.05.065

Goh CH, Nam HG, Park YS (2003) Stress memory in plants: a negative regulation of stomatal response and transient induction of $r d 22$ gene to light in abscisic acid-entrained Arabidopsis plants. Plant J 36:240-255. https://doi.org/10. 1046/j.1365-313X.2003.01872.x

Hauschild R, Hein S (2009) Flooding tolerance of broadleaved trees after an extreme flooding even - A case study from the southern upper Rhine Valley. Allgemeine Forst und Jagdzeitung 180:100-109

Hood WG, Naiman RJ (2000) Vulnerability of riparian zones to invasion by exotic vascular plants. Plant Ecol 148:105-114. https://doi.org/10.1023/A:1009800327334

Hook DD, Brown CL (1973) Root adaptations and relative flood tolerance of five hardwood species. For Sci 19:225-229. https://doi.org/10.1093/forestscience/19.3.225

Leyer I (2004) Effects of dykes on plant species composition in a large lowland river floodplain. River Res Appl 20:813-827. https://doi.org/10.1002/rra.795

Mommer L, Visser EJW (2005) Underwater photosynthesis in flooded terrestrial plants: a matter of leaf plasticity. Ann Bot 96:581-589. https://doi.org/10.1093/aob/mci212

Mosner E, Weber A, Carambia M, Nilson E, Schmitz U, Zelle B, Donath T, Horchler P (2015) Climate change and floodplain vegetation-future prospects for riparian habitat availability along the Rhine River. Ecol Eng 82:493-511. https://doi.org/10.1016/j.ecoleng.2015.05.013

Pires HRA, Franco AC, Piedade MTF, Scudeller VV, Kruijt B, Ferreira CS (2018) Flood tolerance in two tree species that inhabit both the Amazonian floodplain and the dry Cerrado savanna of Brazil. AoB Plants. https://doi.org/10.1093/ aobpla/ply065

Polomski J, Kuhn N (1998) Wurzelsysteme. Brimensdorf, Erdgenössische Forschungsanstalt für Wald, Schnee und Landschaft Bern-Stuttgart-Wien, 269-273.

Puri ML, Sen PK (1985) Nonparametric Methods in General Linear Models.

Quinn GP, Keough MJ (2002) Experimental Design and Data Analysis for Biologists. Cambridge University Press.

R Development Core Team (2017) R: A Language and Environment for Statistical Computing. R Foundation for Statistical Computing. http://www.R-project.org

Richardson DM, Holmes PM, Esler KJ, Galatowitsch SM, Stromberg JC, Kirkman SP, Pyšek P, Hobbs RJ (2007) Riparian vegetation: degradation, alien plant invasions, and restoration prospects. Divers Distrib 13:126-139. https://doi.org/10.1111/j.1366-9516.2006.00314.x

Rood SB, Gourley CR, Ammon EM, Heki LG, Klotz JR, Morrison ML, Mosley D, Scoppettone GG, Swanson S,
Wagner PL (2003) Flows for floodplain forests: a successful riparian restoration. BioScience 53:647. https://doi. org/10.1641/0006-3568(2003)053[0647:FFFFAS]2.0. $\mathrm{CO} ; 2$

Rothmaler W, Jäger EJ, Müller F, Ritz CM, Welk F, Wesche K (2017) Rothmaler - Exkursionsflora von Deutschland Gefäßpflanzen: Atlasband. 13. Auflage, Berlin (Springer)

Schindler M, Jungmann L, Donath TW, Ludewig K (2020) Influence of flooding duration and aeration on saplings of ten hardwood floodplain forest species. PLoS One 15:e234936. https://doi.org/10.1371/journal.pone. 0234936

Siebel HN, Bouwma IM (1998) The occurrence of herbs and woody juveniles in a hardwood floodplain forest in relation to flooding and light. J Veg Sci 9:623-630. https://doi.org/ $10.2307 / 3237280$

Starfinger U, Kowarik I, Nehring S (2011) Artensteckbrief Acer negundo. https://neobiota.bfn.de/handbuch/ gefaesspflanzen/acer-negundo.html. Accessed 24 May 2019

Streng DR, Glitzenstein JS, Harcombe PA (1989) Woody seedling dynamics in an east texas floodplain forest. Ecol Monogr 59:177-204. https://doi.org/10.2307/2937285

Striker GG (2012) Time is on our side: the importance of considering a recovery period when assessing flooding tolerance in plants. Ecol Res 27:983-987. https://doi.org/10. 1007/s11284-012-0978-9

Tahkokorpi M, Taulavuori K, Laine K, Taulavuori E (2007) After-effects of drought-related winter stress in previous and current year stems of Vaccinium myrtillus L. Environ Exp Bot 61:85-93. https://doi.org/10.1016/j.envexpbot. 2007.03.003

Tang ZC, Kozlowski TT (1984) Water relations, ethylene production, and morphological adaptation of Fraxinus pennsylvanica seedlings to flooding. Plant Soil 77:183-192. https://doi.org/10.1007/BF02182922

Tockner K, Stanford JA (2002) Riverine floodplains: present state and future trends. Environ Conserv. https://doi.org/ 10.1017/S037689290200022X

Toner M, Keddy P (1997) River hydrology and riparian wetlands: a predictive model for ecological assembly. Ecol Appl 7:236-246. https://doi.org/10.1890/10510761(1997)007[0236:RHARWA]2.0.CO;2

Vreugdenhil SJ, Kramer K, Pelsma T (2006) Effects of flooding duration, -frequency and -depth on the presence of saplings of six woody species in north-west Europe. For Ecol Manag 236:47-55. https://doi.org/10.1016/j.foreco.2006. 08.329

Walter J, Nagy L, Hein R, Rascher U, Beierkuhnlein C, Willner E, Jentsch A (2011) Do plants remember drought? Hints towards a drought-memory in grasses. Environ Exp Bot 71:34-40. https://doi.org/10.1016/j.envexpbot.2010.10. 020

Zacharias D, Breucker A (2008) Die nordamerikanische RotEsche (Fraxinus pennsylvanica MARSH.) - zur Biologie eines in den Auenwäldern der Mittelelbe eingebürgerten Neophyten. Braunschweiger Geobotanische Arbeiten 9:499-529

Zhou W, Chen F, Meng Y, Chandrasekaran U, Luo X, Yang W, Shu K (2020) Plant waterlogging/flooding stress responses: From seed germination to maturation. Plant Physiol 
Biochem 148:228-236. https://doi.org/10.1016/j.plaphy. 2020.01.020

Zweifel R, Etzold S, Sterck F, Gessler A, Anfodillo T, Mencuccini M, von Arx G, Lazzarin M, Haeni M, Feichtinger L, Meusburger K, Knuesel S, Walthert L, Salmon Y, Bose AK, Schoenbeck L, Hug C, De Girardi N, Giuggiola A, Schaub M, Rigling A (2020) Determinants of legacy effects in pine trees - implications from an irrigation-stop experiment. New Phytol 227:1081-1096. https://doi.org/ 10.1111/nph.16582

Publisher's Note Springer Nature remains neutral with regard to jurisdictional claims in published maps and institutional affiliations. 